\title{
Relationship between Social Anxiety and Parental Authority among College of Education Students' at SQU
}

Hilal Z. Al- Nabhani* \& Abdulhameed S. Hassan

Sultan Qaboos University, Sultanate of Oman

\begin{abstract}
The purpose of this study was to explore the relationship between parental authority and social anxiety. The study attempted to answer the following question: Are there significant differences in social anxiety due to parental authority factors: (support, control, psychological control, emotion and accomplishment of missions)? Data was collected from 172 students of College of Education at Sultan Qaboos University. The Parental Authority Questionnaire (PAQ), and Social Anxiety Scale (SAS) were used to assess variables. To answer the study question, regression analysis was used. Findings indicated that there was significant relationship between parental authority and social anxiety in several domains. The findings also revealed that there were significant differences in social anxiety due to mother authority and student's gender.
\end{abstract}

Keywords: University students, parental authority, gender, social aniety.

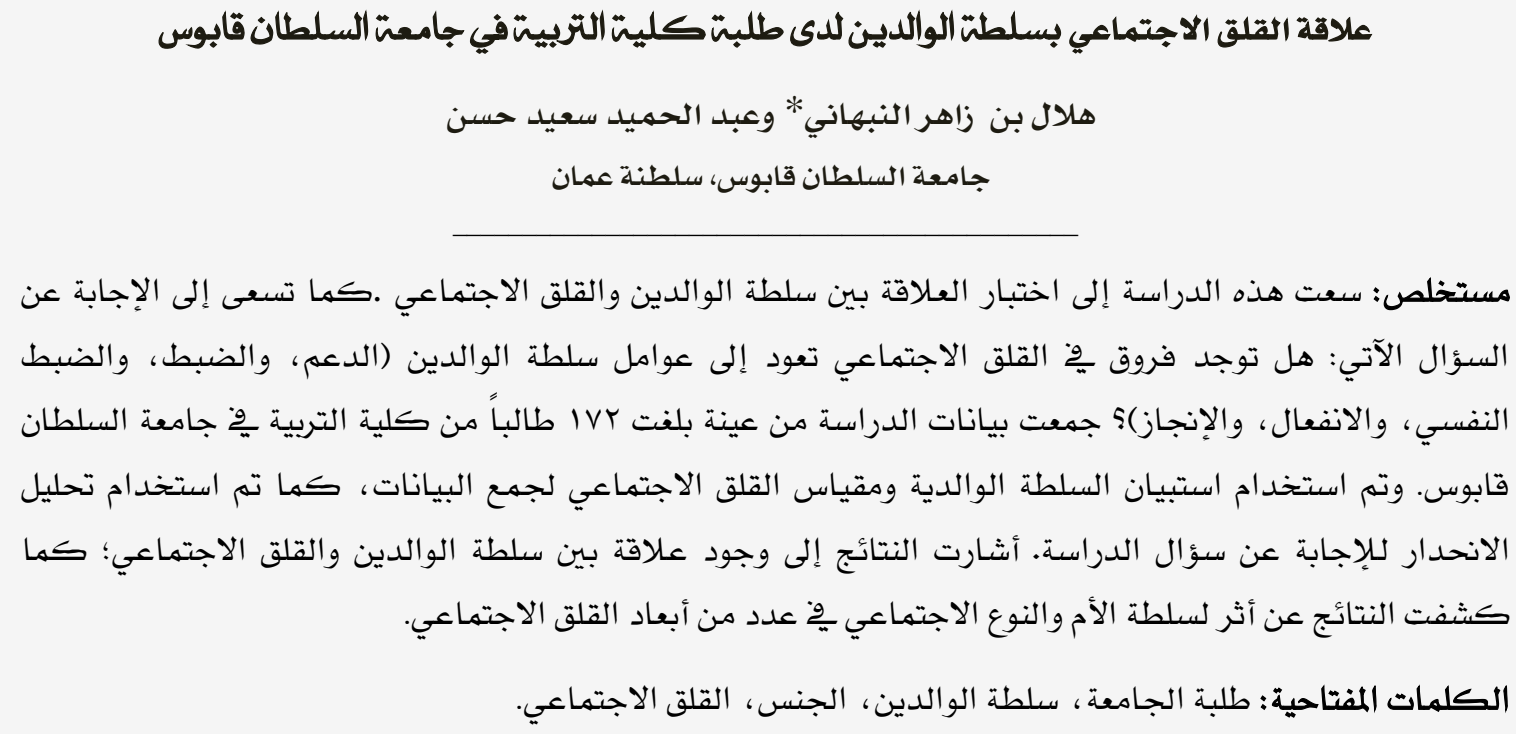

*munabh@squ.edu.om 
Anxiety disorders are among the most common mental health problems experienced by children and young people (Costello, Egger, \& Angold, 2005).Social anxiety is the second most common anxiety disorder in adults (Kessler et al.,2005). According to the diagnostic criteria; social anxiety disorder (SAD), which is also referred to as Social Phobia is one of the six major anxiety disorders listed in the Diagnostic and Statistical Manual of Mental Disorder (DSM-V; APA, 2013). The social anxiety disorder is considered as marked and persistent fear of social or performance situation (Sparrevohn and Rapee, 2009). Research revealed that the most common mental health disorders are mood and anxiety disorders, affecting $6 \%$ of the adolescent population in the United States (Byrne, 2000). In Canada, anxiety disorders are the most common of all mental health problems, affecting one in 10 people, children and adults (Canadian Mental Health Association- CMHA, 2010).

Social anxiety is a general term that might be a result of social conditions. When social anxiety causes problems, it is called social phobia which also includes some symptoms existing in other disorders as shyness and fears caused by criticism, embarrassment, or rejection of others. SAD may lead to high risks of social danger causing disntegration or disturbance in social relationship (Hanlon, 2011).

SAD was examined by several studies. In literature, it was defined as social apprehension which leads to avoiding social situations accompanied by excessive obsession, rejection or embarrassment. Heimberg and Becker (2002) indicated that social anxiety is excessive fear of some social situations, so students with social anxiety demonstrated weak acedemic performance in different classroom activities specially in formal speech and classroom presentation.

SAD is considered a psychological state resulting from fear of negative assessment (Clark \& Wells, 1995). Social fears are common among normal people and may range from simple to high (Ruscio, et al 2008). Parents are considered one of the important factors in the protection of their children from social anxiety. Several studies (e.g., Barnett,et al., 2004, Grcco \& Morris, 2002; Lieb, et al, 2000; Mcloed, Wood \& Weisz, 2007 and Wood,
Mcloed, Sigman, Hwang \& Chu, 2003) emphasized that there was a relationship between the parental stereotype of excessive protection and high control and social anxiety. However, these findings were not harmonic with the findings of a study conducted by Ballash, Pernble, Usui, Buckley and WoodruffBorden (20o6) which indicated an existing relationship between a family environment characterized by empathy, behavioural control, excessive protection and social anxiety symptoms.

Research in related literature signified that environmental conditions play an important role in developing social anxiety particularly in children because of early childhood experiences perceived as threatening situations, these painful situations cause negative feelings in children which are considered as symptoms of social anxiety (Beauchaine \& Hinshaw, 2013). The findings of several studies suggested that parenting style followed by negative methods and treatments may lead to increased social anxiety in their children (e.g., Akinsola \& Udoka, 2013, Ballash, Pemble, Buckly \& Woodruff - Borden, 2006; kulaksizoglu,1998). SAD may be caused by many factors, such as: negative and aversive experiences like: shyness, painful or vocational events, harsh treatment and lack of social skills. In addition, parental rejection, negligence, aggression, lack of warmth and intimacy, and inadequate adaptation are also other sources that may elicit social anxiety (Leahy \& Holland, 2000; Zimmer-Gembeck, Nesdale, 2013; Rudoloph, 2013).

Patterns of parenting received a great attention in research. (Chan and Chan, 2009; Coln, Jordan and Mercer, 2011; Darling and Steinberg, 2013) asserted the importance of parental support and warmth responses in order to achieve positive results in their children. This is considered as an assessment of the parents' behavior ranging from a continuous amount of independence to complete control of children's behavior especially during adolescence (Driscoll, Russell and Crockett, 2008).

The results of this systematic review provided fairly consistent preliminary evidence for an association between anxiety and perceived parental control and anxious parenting in adolescence. (Waitea, Whittingtonb \& Creswella, 2014). 
In addition, parental practices played an important role in creating SAD. This importance was shown in some research, such as: (Andrews, et al.,2003; Erkan, 2002; Cagdas \& Secer, 2004; Yavuzer, 2005 and Baldwin, Mcintyre \& Hardway ,2007); which stressed that the authoritative parenting style may make the child's beliefs irrational and lead to lack in his/her ability to control threatening events. As a result of these events, the children are motivated to avoid diverse social situations.

In this regard, Erozkan(2012); Marnnuzza, et al, ( 2002) and Rudolf ( 2013) maintained that the rejection style provided by parents might lead to social and emotional disorders. The findings pointed out that passive parental practices provoked anxiety and led to symptoms of depression and social anxiety (Kuhar-Meaka , 2010).

The findings of a study conducted by (Daerling and Steinberg (1993); Esther (2013); Turner, Chadler \& Heffer (2009); Chang,Oleson,Sameroff \& Sexton (2009);Drisecoll, Russell \& Crocket (2008) indicated that the authoritative parenting style was an important factor in causing social anxiety in children.

McLeod, Wood, \& Weisz (2007) studied parental rejection which involves withdrawal from or hostility towards the child and a lack of warmth, involvement, emotional support or reciprocity with the child. They hypothesized that this rejection undermines the child's emotion regulation, thus increasing his/her sensitivity to anxiety. From the meta-analysis of 47 studies examining the association between childhood anxiety and parenting - a medium sized association between parental control and child anxiety, but a small association between parental rejection and child anxiety.

Wood, et al. (2007) stressed that parental control of their children may be frightening and insecure, so this negative level of control may get the child inassertive and cause a sense of anxiety. Taylor, Jang, Stewart and Stein (2008) emphasized that hereditary factors, learning experiences and personal factors are all crucial determinants of high social anxiety.

There are many change sex pertinence by individuals throughout their lives. These changes may occur during the adolescence stage which is characterized by a variety of emo- tional problems and difficulties that are strongly related to the quality of the relationship between parents and children. (Lerner, et al., 1996).

Consequently, Bandura (1997) considered that it is necessary to clarify the factors affecting the parental stereotypes. The nature and quality of the interactions between parents and children continue to affect them in childhood, adolescence and adulthood. Among the factors affecting social anxiety is the type of the relation between adolescents and their parents. In this regard, Darling, Cumsille, Caldwell \& Dowdy (2008); Darling, Cumsille \& Martinez (2008) believed that adolescents viewed their parents' authority as illegal in their developments.

\section{Statement of problem}

As mentioned above, it is clear that SAD is a social problem affecting individuals in different degrees, and there are several factors causing it such as: painful early childhood experiences, child's personality, continuous frustrations, stresses, parenting styles, failure experiences specially in academic domain, and learning environment. These factors may contribute to shape social anxiety in university students. The rationale beyond conducting this study is that related literature in Middle East societies mainly depended on investigating the parental styles toghether in the same tool because our belief and cultural system see that the parental authority is only governed or determined by fathers' authority, and mothers are subordinate for this authority, but this study was to measure fathers' style and mothers' styles seperately. This method gives power for exploring differences among fathers' styles and mothers' styles in parenting and the role of these styles in shaping personality and causing various problems and disorders, such as social anxiety. Assadi, Zokaei, Kaviani, Mohammadi and Ghaeli (2007) noticed that In Middle East cultures not only provide information regarding parenting in other societies but also broaden our crosscultural database so as to better understand the role of cultural factors in parenting. The current study mainly focused on the invistigation of parenting styles as one of factors that cause SAD and social anxiety in the students of Sultan Qaboos University. Howerver, the study attempted to answer the following question: Are there significant 
differences in social anxiety due to parental authority factors: (support, control, psychological control, emotion and accomplishment of missions)?

\section{Method}

\section{Participants}

A pilot sample of 328 students in all levels randomly chosen from the total number of students enrolled in the college of education $(\mathrm{N}=1644)$ with percentage of $(20 \%)$ was used to assess construct validity of the Parental Authority questionnaire (PAQ). A convenience sample of 172 students from the second level at College of Education at Sultan Qaboos University was used for the study. This sample consisted of 82 Male and 90 female represented all college majors. Study tools were sent to the total number of 371 students at this level, and they were asked to respond to the items of these scales. 172 students responded to both scales and returned back them to the researchers. The participants represented $46 \%$ of the total number of the targeted students.

\section{Instruments}

\section{The Parental Authority questionnaire( PAQ)}

Parental authority was assessed based on parental seperation. This separation was found to be important in parenting ; because of the differences between fathers and mothers in parenting methods in dealing with adolescents (Meunier et al.,2011). The items of the Parental Authority questionnaire (PAQ) were constructed based on two related scales (Kuhar, 2012; Reitman, Rhode, Hupp and Ahobello,2002). The scale consisted of 35 items distributed into five subscales: support, control, psychological control, emotion and accomplishment of missions. The PAQ items were responded according to a 5- point Likert scale : ( strongly agree $=5$, agree $=4$, neutral $=3$, disagree $=2$, strongly disagree1 $=)$. The face validity scale was assessed by a panel of referees whose specializations are measurement and educational psychology. They were asked to assess the items based on the extent to which each is correlated to the concept of parental authority. The cut-off point of $80 \%$ was used to assess this correlation. The construct validity was also assessed by exploratory factor analysis. The loading rate of 0.30 was used to assess items' loadings. Factor analysis accounted for $\% 48,066$ and 48.066 of the total variance in fathers and mothers successively. Analysis extracted five factors (subscales), and the item loadings ranged from $(0.328-0.709)$. Consequently, the following items: $(3,5,6,10$, 11 in fathers), and (3, 4, 8, 11 in mothers) were deleted. Some extracted factors for the fathers were different from those of the mothers, and the others are similar. The extracted factors for the fathers were: (support, psychological control, open discussion of Ideas, control, emotion), and those for the mothers were: (support, control, psychological control, emotion, accomplishment). The results of factor analysis are illustrated in table 1.

Table1

Factor loadings on authority father and authority mother

\begin{tabular}{|c|c|c|c|c|c|c|c|c|c|c|c|c|}
\hline & Fath. & Moth & Fath. & Moth & Fath. & Moth & Fath. & Moth. & Fath. & Moth. & Fath & Moth \\
\hline 1. & & & & .459 & & & .453 & .516 & & & & \\
\hline 2. & & & & & & & .621 & .510 & & & & \\
\hline 3. & & & & & & & .352 & .495 & & & & \\
\hline 4. & & .425 & & & .731 & & & & & & & \\
\hline 5. & & & & & .615 & & & .541 & & & & \\
\hline 6. & & & & & .415 & & & & & & & \\
\hline 7. & & & .478 & .428 & & & & & & & & \\
\hline 8. & .450 & & & & & & & & & & & \\
\hline 9. & & & .495 & .628 & & & & & & & & \\
\hline 10. & & & & & & & .328 & .562 & & .387 & & \\
\hline 11. & & & & & .567 & & & & & & & \\
\hline 12. & .346 & .500 & & & & & & & & & & \\
\hline 13. & & & .594 & .490 & & & & & & & & \\
\hline 14. & & & .388 & .446 & & & & & & & & \\
\hline 15. & & & & & & & & .519 & .562 & & & \\
\hline 16. & & & & .516 & .446 & & & & & & & \\
\hline
\end{tabular}


Table1

Factor loadings on authority father and authority mother

\begin{tabular}{|c|c|c|c|c|c|c|c|c|c|c|c|c|}
\hline & Fath. & Moth & Fath. & Moth & Fath. & Moth & Fath. & Moth. & Fath. & Moth. & Fath & Moth \\
\hline 17. & & .643 & & & & & .455 & & & & & \\
\hline 18. & .643 & .709 & & & & & & & & & & \\
\hline 19. & & & .648 & .639 & & & & & & & & \\
\hline 20. & & & .621 & .498 & & & & & & & & \\
\hline 21. & & & & & & & .478 & .554 & & & & \\
\hline 22. & .709 & .696 & & & & & & & & & & \\
\hline 23. & & & .519 & & & & & & & & & .707 \\
\hline 24. & & & & & & & & & .398 & .588 & & \\
\hline 25. & .696 & .586 & & & & & & & & & & \\
\hline 26. & & & & & & & & & .591 & .788 & & \\
\hline 27. & & & .350 & & & & & & & & & \\
\hline 28. & .586 & .604 & & & & & & & & .770 & & \\
\hline 29. & & & .500 & & & & & & & & & .646. \\
\hline 30. & .605 & .635 & & & & & & & & & & \\
\hline 31. & & & .644 & & & & & & & & & .355 \\
\hline 32. & .646 & .655 & & & & & & & & & & \\
\hline 33. & & & .377 & & & & & & & & & .399 \\
\hline 34. & .637 & .727 & & & & & & & & & & \\
\hline 35. & .592 & .656 & & & & & & & & & & \\
\hline$\%$ of & \%14. & \%14. & $\% 11$. & \%9.9 & $\% 7.1$ & & $\% 9.20$ & \%9.95 & $\% 5.99$ & $\% 6.81$ & & $\% 5.4$ \\
\hline $\begin{array}{l}\text { Vari- } \\
\text { ance }\end{array}$ & 3 & 3 & 4 & 0 & 1 & & & & & & & 0 \\
\hline $\begin{array}{l}\text { Eigen } \\
\text { values }\end{array}$ & 5.58 & 5.63 & 4.84 & 4.23 & 3.03 & & 4.09 & 4.08 & 2.79 & 3.19 & & 2.19 \\
\hline
\end{tabular}

Reliability was estimated by internal consistency - Cronbach Alpha. The values of Cronbach Alpha were $0.83 ; 0.81 ; 0.86 ; 0.82$. And 0.81 for the five subscales for fathers and $0.85,0.83,0.80,0.81$ and 0.80 for the five subscales for mothers.

\section{Second: The social anxiety scale}

The Social Anxiety Scale was constructed based on the literature of Olivares et al. (2005) and Vigil (2009). The scale consisted of 40 items assessing the different situations causing social fears especially with those in social environment and social interactions. The SAS items are answered according to a 3-point Likert scale: (always $=3$, sometimes $=2$, never $=1)$. The face validity scale was assessed by a panel of experts whose specializations were measurement and educational psychology. They were asked to assess the items based on the extent to which each is correlated to the concept of parental authority. The cut-off point of $80 \%$ was used to assess this correlation. Reliability was estimated by internal consistency - Cronbach Alpha. The value of Cronbach Alpha was 0.85 which means that the scale is accepted psychometrically.

\section{Results and discussion}

To test the study hypotheses; means and standard deviations were calculated. The conditions of multiple regression analysis such as: homogeneity and degree of correla

tions was achieved. The significance of correlations between parental authority and social anxiety was achieved. After that we found the Means, standard deviations, and results of multiple regression which are shown in tables 2 and 3.

Table 2 shows that means of subscales of the PAQ for fathers and mothers were above average 3, but for social anxiety; Means were below the average 2 .

To meet the conditions of multiple regression analysis, correlations among all independent study variables were calculated, and found to be statistically significant. The values were not too big, and ranged between 0.03 and 0.492 , but did not reach 0.70 . This is consistent with the second condition of multiple regression analysis that the sample should be selected randomly. This (Randomness) is shown in diagram 'scatter plot' as illustrated in the appendex. 
Table 2

\begin{tabular}{lcc}
\multicolumn{1}{c}{ Means and standard deviation of the dependent and independent variables } \\
\hline Variable & $\mathrm{M}$ & $\mathrm{SD}$ \\
\hline Independent : & & \\
Parental authority (father's role): & 3,4371 & .41707 \\
Support & 3,1920 & .38903 \\
Psychological control & 3,5106 & .60998 \\
Open discussion of ideas. & 2,9980 & .46189 \\
Control & 3,3706 & .66116 \\
emotion & & .57500 \\
Parental authority (mother's role): & 3.9380 & .59504 \\
Support & 3.4625 & .63181 \\
control & 2.9088 & .73739 \\
psychological control & 2.7662 & .80599 \\
emotion & 3,3088 & .43767 \\
Accomplishment of missions & 2.7744 & 28404. \\
depended : Social anxiety & 1.7440 & \\
\hline
\end{tabular}

After verifying these conditions ; the regression analysis showed that three of the independent variables had an effect on the dependent variable (social anxiety) of the sample, and these variables were: the mother's support $\left(R^{2}=0.374\right)$, mother's psychological control $\left(R^{2}=0.192\right)$ and student gender $\left(R^{2}=\right.$ 0.109). These results are shown table 3 .

To determine the significant effect of the two styles (Support and psychological control) of mothers on students' social anxiety according to gender, regression analysis was used. Its results are shown in table 4.

Table 4 shows the effect of the mother's styles of support and psychological control on social

anxiety was significant on daughter comparing to sons in terms of social anxiety

level. The value of the effect of social support $(\mathrm{t}=-3.08, \mathrm{p}<0.003)$. As for the psychological control style $(\mathrm{t}=-4.3, \mathrm{p}<0.001)$. The effect of both styles on son's social anxiety was positive, but not significant.

These findings may be due to the mother's psychological, emotional, mental maturity, and interaction with the social environment that helps the mother to be initiative to control and direct the children's behavior. The social environment plays an important role in raising and taking care of her children. In this way, the mother creates a climate of trust, and After verifying these conditions; the regression analysis showed that three of the independent variables had an effect on the dependent variable (social anxiety) of the sample, and these variables were: the mother's support $\left(\mathrm{R}^{2}=\right.$ $0.374)$, mother's psychological control $\left(\mathrm{R}^{2}=\right.$
$0.192)$ and student gender $\left(R^{2}=0.109\right)$. These results are shown table 3 .

To determine the significant effect of the two styles (Support and psychological control) of mothers on students' social anxiety according to gender, regression analysis was used. Its results are shown in table 4 .

Table 4 shows the effect of the mother's styles of support and psychological control on social anxiety was significant on daughter comparing to sons in terms of social anxiety level. The value of the effect of social support $(t=-3.08$, $\mathrm{p}<0.003)$. As for the psychological control style $(\mathrm{t}=-4.3, \mathrm{p}<0.001)$. The effect of both styles on son's social anxiety was positive, but not significant.

These findings may be due to the mother's psychological, emotional, mental maturity, and interaction with the social environment that helps the mother to be initiative to control and direct the children's behavior. The social environment plays an important role in raising and taking care of her children. In this way, the mother creates a climate of trust, and assertiveness to encourage them to assume responsibility and to get ready for the future.

The study results were in agreement with a study conducted by Tiffany (2008) who mainly focused on identifying the impact of maternal deprivation and its negative impact on children's behavior. In her study, Tiffany concluded that the mother's psychological maturity contributed in the children's psychological well-being and the deprivation of the mother whose children may face many problems such as tension, depression, anxiety and instability. This finding is consistent with research showing that parental support is correlated to many 
children's positive outcomes such as children's school grades, internal control, lower anxiety, positive self- control (e, g., Assadi et al, 2001, Beshart et al, 20, Mcloed, Wood \& Weisz, 2007, Smith \& college, 2007).

These positive effects related to mothers' parenting authority may result in some cultural changes in the Omani society because of the increasing numbers of the education opportunities available nowadays for women. This change in the education trend in society may influence people's psychological health and social anxiety had its own effect on adolescents' development. This direct effect of

mothers on adolescents' well-being was one of the findings reported by Chang, Oison, Sameroff, and Sexton (2011) who found that maternal use of positive discipline did not predict a child's externalizing behaviors. This study is consistent with (Alkholif, 2002; Aldhafri, 2011) in the same target culture (Oman). This may indicate that the mother's concerns of support and psychology control are more apparent in the Omani society than the father's support and psychology control. The current study is consistent with the cumulative researchers (e.g., Frank et al., 2010; Hannum \& Dovork, 2004) showing that it is important to examine each parental authority style separately to identify the degree of differences existing between the father's effect and the mother's on adolescents' outcomes.
Additional findings revealed some ongoing changes in the Middle -Eastern parent rules (Assadie, et al., 2007; Besharart, et al., 2011).

Concerning the gender differences found in the present study, they were in line with most of the studies that dealt with this issue (i.e., Rudolph \& Zimmer-Gembeck, 2014; Sueda, 2009; Edelmann, 2005). These gender differences may be due to the influence of the culture and society. For example, the Arab woman heavily adheres to society values because she likes to appear socially nice and agreeable in front of others. If that does not take place, she feels ashamed, confused and embarrassed, particularly among university young women. This case is the most important symptom of social anxiety.

\section{Conclusion}

It was concluded that means of parenting authority factors for students were above the average (3) except (psychological control, emotion, accumulation rate), and these factors had low means in mother's authority. In addition, there were factors affecting social anxiety according to MRA- such as the mother's support, mother's psychological control and gender. The effect of the mother's styles of support and psychological control on social anxiety was more significant on daughters than on sons in terms of decreasing social anxiety. In my opinion such above conclusion attributed

Table 3

Findings of the regression analysis of the independent variables at the social - anxiety level (dependent variable)

\begin{tabular}{lccccc}
\hline Independent variable & $\mathrm{R} 2$ & $\mathrm{R} 2 \mathrm{Adj}$. & Beta & $\mathrm{t}$ & Sig. \\
\hline Support (father) & -0.026 & 0.061 & -0.38 & -0.427 & 0.670 \\
Psychological control (father) & 0.124 & 0.072 & 0.169 & 1.724 & 0.087 \\
Open discussion (father) & -0.053 & 0.036 & -0.114 & -1.451 & 0.149 \\
Control (father) & 0.028 & 0.051 & 0.045 & 0.554 & 0.587 \\
Emotion (father) & 0.011 & 0.039 & 0.026 & 0.292 & 0.771 \\
Support (mother) & 0.374 & 0.198 & 0.252 & 2.852 & 0.005 \\
Control (mother) & -0.028 & 0.046 & -0.059 & -0.611 & 0.542 \\
Psychological control (mother) & -0.192 & 0.102 & -0.228 & -2.627 & 0.009 \\
Emotion ( mother) & -0.015 & 0.029 & -0.040 & -0.540 & 0.590 \\
Accomplishment of Missions (mother) & 0.033 & 0.030 & 0.094 & 1.101 & 0.273 \\
Gender & 0.109 & 0.048 & 0.173 & 2.275 & 0.024 \\
\hline
\end{tabular}

Table 4

Standardized beta values for mother's support and psychological control on social anxiety

\begin{tabular}{llllrr}
\hline Sex & Parental authority & B & Beta & t & Sig. \\
\multirow{4}{*}{ male } & (Constant) & 1.798 & & 5.587 & .000 \\
& Support & -.009 & -.205 & -1.382 & .174 \\
& Psychological control & -.011 & -.249 & -1.679 & .101 \\
female & (Constant) & 1.789 & & 9.142 & .000 \\
& BB1 & -.011 & -.252 & -3.085 & .003 \\
& BB3 & -.020 & -.337 & -4.130 & .000 \\
\hline
\end{tabular}

Dependent variable: Social anxiety 
to cultural changes for mothers in Sultanate of Oman. Thus, these changes play an important role on psychological control and social support which results in eliminating the level of social anxiety in students.

\section{Recommendations and suggestions}

First: Studying the parental practices that predict social anxiety in all dimensions.

Second: Fathers should assume responsibility in taking care of their boys and girls to eliminate social anxiety in them in future.

Third: Focusing on the negative effects of parental practices that lead to social anxietygenerated disorders with regard to university students.

Fourth: Conducting future studies in other samples or target groups to determine the effect of parental treatment on social anxiety.

\section{References}

Akinsola, E. \& Udoka, P. (2013). Parental Influence on Social Anxiety in Children and Adolescences: Its Assessment and Management Using Psychodrama. Psychology, 4, 246-253. Doi: 10. 4236. 2013. 43A037.

Aldhafri, S. (2011). Self-efficacy and physical self - concept as mediators of parenting influence on adolescents school and health wellbeing, Journal of Psychology in Africa, 21(4), 511-520.

Alkholifi, S. (2002). The role of fathers in child rearing as perceived by a sample of mothers in Qatar and UAE societies. Journal of Education Research Center, 11(22), 59-91.

Andrews, G., Creamer, M., Crino, R., Hunt, C., Lampe, L., \& Page, A. (2003). The treatment of anxiety disorders: Clinician guides and patient manuals (2nd Ed.). Melbourne: Cambridge University.

Assadi, S., Zokaei, N., Kaviani, H., Mohammadi, M.,Ghaeli,P.,Gohari, M. \& Van de Vijver, F.(2007). Effect of sociocultural context and parenting style on scholastic achievement among Iranian adolescents. Social Development, 16(1), 169-180.

Baldwin, M., Mcintyre, A. \& Hardway, E. (2007). Perceived parenting styles on Col- lege student's optimism. College Student Journal, 41(3), 550 - 557.

Ballash, G., Pemble, K., Usui, M., Buckley, A. F., \& Woodruff- Borden, J. (2006). Family functioning, perceived control, and anxiety: a meditational model. Journal of Anxiety Disorder, 20, 486-497.

Bandura, A. (1997). Self-efficacy: The exercise of control. New York: W.H.Freeman.

Besharat, M., Azizi, K. \& Poursharifi, I. (2011). The relationship between parenting styles and children's academic achievement in a sample of Iranian families, Procardia Social and Behavioral Sciences, 15, 1280-1283.

Barnett, D., Kramer, M. L., Casat, D., Conner, M. \& Davidson, J.T. (2004). Efficacy of Olanzapine in social anxiety disorder: a plot study. Journal of Psychopharmacology, 16(4), 365-368. doi: $10.1177 / 026988110201600412$

Byrne, B. (2000). Relationships between anxiety, fear, self-esteem and coping strategies in adolescence. Adolescence, 35, 201215. Retrieved November 10th from

http://www.eric.ed.gov/ERICWebPortal/se arch/detailmini.

Beauchaine, T. P., Hinshaw, Stephen P. (2013). Child and Adolescent Psychopathology (2nd Edition). NJ: Gohn Wiley \& Sons, Inc.

Çağdaş, A. ve Seçer, Z. (2004). Anne baba eğitimi. Konya: Eği- tim Kitabevi. H.

Canadian Public Health Association (2007). Health and Learning. Retrieved May 2nd, 2012 from www.cpha.ca/en/schoolhealth.aspx.

Clark, d. M., \& Wells, A. (1995). A cognitive model of Social phobia in R. G. Heimberg, M. R. liaebwit22, D. A. Hope \& F. R. Schneier (Eds), Social Phobia: diagnosis, assessment and treatment. New York, London: The Guilford press.

Chan, K. \& Chan, S. (2009). Emotional autonomy and perceived parenting style: Relational analysis in the Hong Kong culture context, Asia Pacific Educational Review, 10,433 - 443 . 
Chang H., Olson S., Sameroff A. J. \& Sexton H. (2011). Child effortful control as a mediator of parenting practices on externalizing behavior: evidence for a sexdifferentiated pathway across the transition from preschool to school, Journal Abnormal Child Psychology, 39(1):71-81. doi: 10.1007/s10802-010-9437-7.

Coln, L., Jordan. S.S. \& Mercer, H. (2013). A unified model exploring parenting practices as mediators of marital conflict and children s adjustment, Child Psychiatry and Human Development. 44,419-429. Doi: 10. 1007/s10578-012-0336-8.

Costello, E. J., Egger, H., \& Angold, A. (2005). 10-Year Research Update Review: The Epidemiology of Child and Adolescent Psychiatric Disorders: I. Methods and Public Health Burden. Journal of the American Academy of Child E Adolescent Psychiatry, 44(10), 972-986.

http://dx.doi.org/10.1097/01.chi.0000172552. 41596.6f.

Darling, N., Cumsille, P., Caldwell, L.\& Dowdy, B. (2008). Predicator of adolescents disclosure strategies and perceptions of parental knowledge, Journal Youth Adolescent, 35, 667 - 678.

Darling , N., Cumsille, P. \& Martinez, L. (2008). Individual difference in adolescences beliefs about the legitimacy of parental authority and their own obligation to obey: A longitudinal Investigation, Child Development, 79(4), 1103-1118.

Darling, N. \& Steinberg, L.(1993). Parenting style as context an integrative model, Psychology, Bull, 113(3), 487 - 496.

DSM-V.; APA. (2013). Diagnostic and Statistical Manual of Mental Disorders, 5th ed., Washington DC: APA.

Driscoll, A., Russell, S., \& Crockett, L. (2008). Parenting styles and youth well- being across immigrant generations, Journal of Family Issues, 29(2), 185 - 209.

Edelmann, R. J. (2004). Coping with blushing (2nd ed.). England: Sheldon Press.

Erkan, Z. (2002). Sosyal kayg1 düzeyi yüksek ve düşük ergen- lerin ana baba tutumlarına ilişkin nitel bir çalışma. Çukurova Üniveritesi Sosyal Bilimler En- stitüsü, Enstitü Dergisi/E Dergi ISSI:13, $10,120-1$.

Erozkan, A. (2012). Examination of relationship between anxiety sensitivity and parenting style in adolescents, Educational Sciences: Theory \& Practice, 12(1), 52-57.

Esther, F. (2013). Parental influence on social anxiety in children and adolescents: its assessment and management using psycho drama. Psychology, 4 (34), 246-253.

Frank, G., Plunkett, S. \& Otten, M. (2010).Perceived parenting, self- esteem and general self-efficacy of Iranian American adolescents, Journal of Child and Family Studies, 19,738-746.doi: 10.1007/s10826010-9363.

Hanlon, N. (2010). Information on social anxiety, Retrieved from: http:/ / www. Social anxiety.co.uk/ downloads/ information on Social Anxiety. Pdf.

Hannum, J. \& Dvorak, D. (2004). Effect of Family conflict divorce, and attachment patterns on the psychological distress and social adjustment of college freshmen, Journal of College Student Development,45(1),27-42.

Heimberg, R. \& Becker, R., (2002). Cognitive behavioral group therapy for social phobia, New York: Guilford Press.

Kessler, R. C., Berglund, P. A., Demler, O., Jin, R., \& Walters, E. E. (2005). Lifetime

Prevalence and age-of-onset distributions of DSM-IV disorders in the National

Co morbidity Survey Replication (NCS-R). Archives of General Psychiatry, 62, 593-602.

Kuhar, M. (2010). Parental authority styles In adolescent parent relationships. In: DiskursKindheits- und Jugendforschung, 5 (3), 321-336. URN: http:/ / nbnresolving.de/urn:nbn: de:0168-ssoar354694.

Leahy, R. \& Holland, S. (2000). Treatment plans and interventions for depression and anxiety disorders. New York: Guilford Press.

Lerner, R. M., Lerner, J. V., von Eye, A., Ostrom, C. W., Nitz, K., Tolwar-Soni, R., \& Tubman, J. G. (1996). Continuity and discontinuity across the transition of early adolescence: A developmental contex- 
tual perspective. In J. A Graber, J.

Brooks- Gunn, \& A. C. Petersen (Eds.), Transitions through adolescence: Interpersonal domains and context (pp. 3-22). New Jersey: Law-fence Erlbaum 33. F.

Lieb, R., Wittchen, H., Hofler, M., Fuetsch, M., Stein, B. \& Merikangas, K. R. (2000). Parental psychopathology, Parenting style, and the risk of social phobia in offspring a prospective- Longitudinal community study, Arch gen Psychiatry, 57(9),859-866. Doi: 10.1001/ archpsyc, $57(9), 859$.

Mannuzza, S., Klein, Moulton, L., Scarfone, N., Malloy, P., Vosburg, S. K. (2002). Anxiety sensitivity among children of parents with anxiety disorder: a controlled high risk study. Journal Anxiety Disorder, 16, 135-148.

Meunier, J., Roskam, I., stivenart, M. , Moorteie, G., Browne, D., \& Kumar, A. (2011). Externalizing behavior trajectories: The role of parenting, sibling relationships and child personality. Journal of Applied Development Psychology, 32,20-33. Doi: 10-1016/j. appdev.2010.09.006..

McLeod, D., Wood, J., \& Weisz, J. R. (2007). Examining the association between parenting and childhood anxiety: A metaanalysis. Clinical psychology review, 27(2), 155-172.

http:/ /dx.doi.org/10.1016/j.cpr.2006.09.0 02

Olivares, J., Garcia-lopez, L. J., Hidalgo, M. D. \& Caballo, V. E. (2004). Relations among social anxiety measures and their invariance, A Confirmatory factor analysis. European Journal of Psychological Assessment, 20, 172-179.

Reitman, D., Rhode, P. C., Hupp, S. D. A. \& Altobello, C.(2002). Validation of the parental authority questionnaire - revised, Journal of Psychology and Behavioral Assessment, 24(2), 119-127.

Rudolph, J. \& Zimmer-Gembeck, M. J. (2013). Parent relationships and adolescent's depression and social anxiety: indirect association via emotional sensitivity to rejection threat. Australian Journal of Psychology. 66,110-121.
Ruscio, A, M., Brown, A., Chin, T., Sareen, j., Stin, B., \& Kessler, C. (2008). Social Fearsand social phobia in The USA: results from The National Comorbidity survey Replication psychological Medicine. 38. 15-20.

Smith, G. \& College, D. (2007).Parenting effects on self-efficacy and self-esteem in late adolescence and how those factors impact adjustment to college. Paper presented at the annual meeting of the Eastern Psychological Association, Philadelphia, and P.A.

Sueda, K. (2009). Social anxiety remediation in Japan and the United States, Intercultural Relation's, 92,110-138.

Taylor, S., Jang, L., Stewart, H., \& Stein, B. (2008). Etio- logy of the dimensions of anxiety sensitivity: A behavioral-get- notice analysis. Journal of Anxiety Disorders, 22, 899-914.

Tiffany, F. (2008). The Effects of Mother's Physical and Emotional Unavailability on Emotion Regulation, Monographs of the Society for Research in Child Development, 59(. 2/3), 208-227.

Turner, E., Chadler, M., \& Heffer, R. (2009). The influence of parenting style, achievement motivation and self - efficacy, on academic performance in college students, Journal of College Student Development, 50 (3), 337-346.

Yavuzer, H. (2005). Ana-baba ve cocuk. İstanbul: Remzi Kitabevi.

Vigil, A. (009) The factorial structure of the 41-item version of the Screen for child anxiety Related Emotional disorders (SCARED) in A Spanish population of 8 to 12 years -old, International Journal of Clinical and Health psychology, 9, 313 -327.

Waitea, P., Whittingtonb, L. \& Creswella, C. (2014). Parent-Child Interactions and Adolescent Anxiety: A Systematic Review. Psychopathology Review, 1(1), 51-76. ISSN 2051-8315 / DOI:10.5127/pr.033213

Wood, J., Mcloed, D., Sigman, M., Hwang, C., \& Chu, C. (2007). Parenting and childhood anxiety: theory, empirical findings, \& future directions, Journal of Child Psychology and Psychiatry, 44, 134-151.

Wood, J., McLeod, D., Sigman, M., Hwang, C., \& Chu, C. (2003). Parenting and 
childhood anxiety: Theory, empirical

findings, and future directions. Journal of Child Psychology and Psychiatry, 44(1), 134151. doi: 10.1111/1469-7610.00106.

Zimmer-Gembeck, J. \& Nesdale, D. (2013). Anxious and angry rejection sensitive, social withdraw, and retribution in high and low ambiguous situation, Journal of Personality, 81.29 -38. Doi:10.1111/j.14676494.2012.00792.x. 


\section{Appendix}

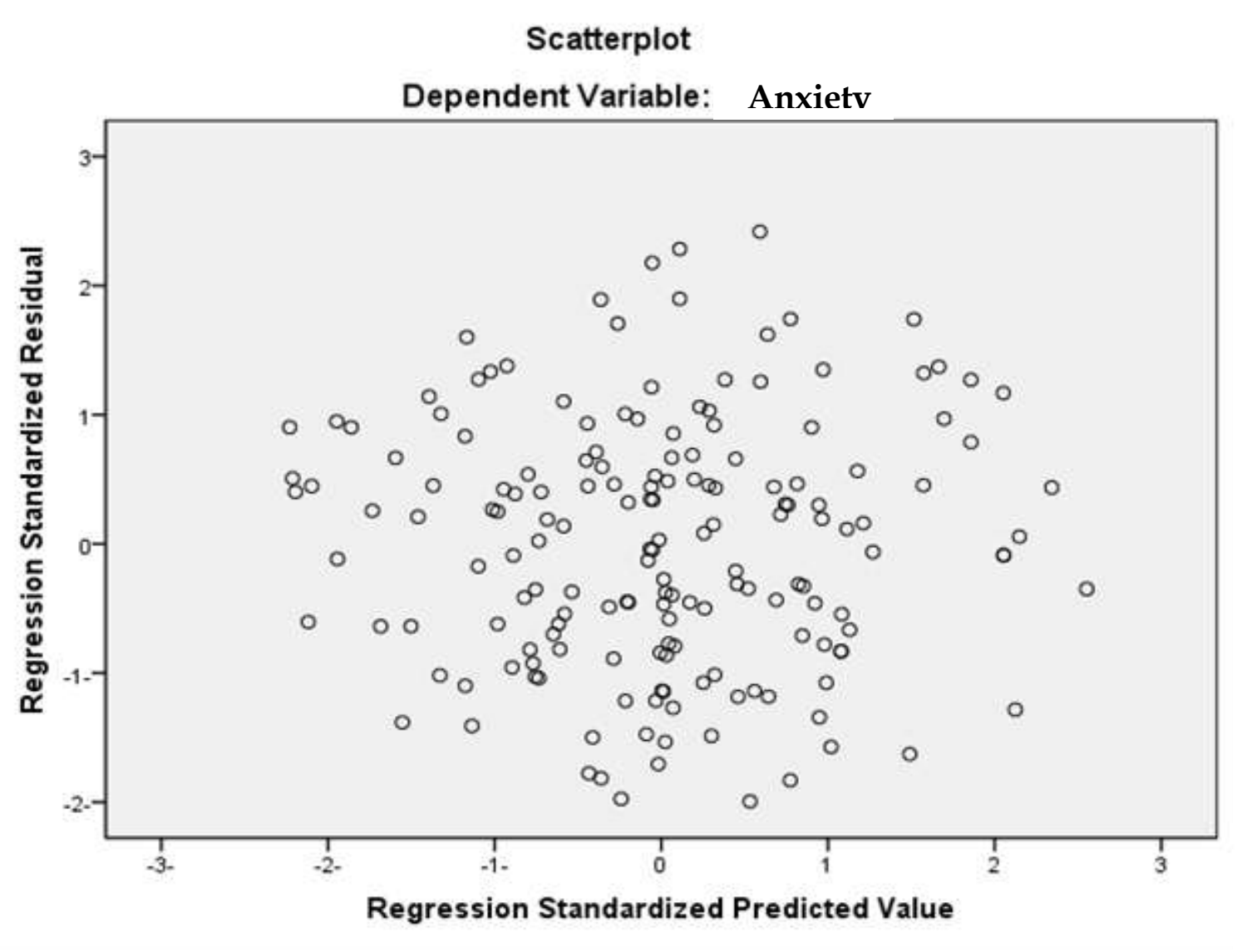

Figure 1

Relationship between social anxiety and parental authority 